\title{
High Temperature Membrane Reactor System for Hydrogen Permeation Measurements and Validation with Pd Based Membranes
}

\author{
S.P.S. Badwal* and F.T. Ciacchi
}

\author{
CSIRO Energy Technology, Private Bag 33, Clayton South 3169, Victoria, Australia
}

\begin{abstract}
Hydrogen separation membranes are under development for integration with a coal gasifier or natural gas reformer for pre-combustion separation of hydrogen and carbon dioxide. Because of the high operating temperatures and pressures, a robust reactor and associated control systems are required for fast screening of membrane materials with a strong emphasis on operator and plant safety. In this paper, the design, construction and commissioning of a reliable membrane reactor and a versatile test station for evaluation of hydrogen permeation membrane materials (metals, ceramics or cermets) at high temperatures and high differential pressures has been described. The membrane reactor system has been designed to operate at temperatures up to $800^{\circ} \mathrm{C}$ and pressure differentials across the membrane to $1.0 \mathrm{MPa}$. The system has multiple levels of safety redundancy built-in which include a range of controls and monitors for both operator and system safety. A number of Pd and Pd-Ag alloys of nominal thicknesses in the 20 and $140 \mu \mathrm{m}$ range were sourced and alumina based porous ceramic support structure were fabricated for evaluation of metal membranes. The test station has been validated with $\mathrm{Pd}$ and $\mathrm{Pd}-\mathrm{Ag}$ alloys of different thicknesses. The data obtained from the reactor for various membrane types and thicknesses are in agreement with those reported in the literature.
\end{abstract}

Keywords: Hydrogen permeation, hydrogen flux, membrane reactor design, coal gasification, gas reforming, gas separation membrane, Pd membrane.

\section{INTRODUCTION}

The future energy mix will slowly shift from fossil fuels to clean and more sustainable energy solutions such as renewable and nuclear energy. Currently the cost of renewable energy is high and there is global concern about building more nuclear power plants. Coal is one of the major fossil fuel resources, with over 250 years of reserves forecast at its current rate of consumption, and will remain a major resource for power generation for many more decades [1]. Thus, for large scale power generation there is an increasing interest in clean coal technologies such as integrated gasification combined cycle (IGCC) and integrated drying gasification combined cycle (IDGCC), which offer substantially higher efficiency in the 40-45\% compared with $30-35 \%$ available from conventional coal fired power plants $[2,3]$. Typically in these new coal fired power plants, coal is gasified with steam and oxygen to produce a mixture of hydrogen and carbon monoxide. In order to keep costs low, high temperature gas cleaning is performed to remove particulate matter followed by the high temperature water gas shift reaction $\left(500^{\circ} \mathrm{C}\right.$ or higher) to convert $\mathrm{CO}$ to carbon dioxide and more hydrogen [4, 5]. Pre-combustion separation of hydrogen offers many advantages as opposed to post-combustion separation of $\mathrm{CO}_{2}$.

*Address correspondence to this author at the CSIRO Energy Technology, Private Bag 33, Clayton South 3169, Victoria, Australia; Tel: +61 39545 2719; Fax: +61 39545 2720; E-mail: Sukhvinder.Badwal@csiro.au
For example, the gas mixture is at high pressures and $\mathrm{CO}_{2}$ is in a concentrated form thus allowing for the most effective and low cost gas separation. Membrane based technologies are attracting substantial global interest for pre-combustion separation of hydrogen and carbon dioxide [6-11]. Thus, suitable membrane materials, with high permeation rates for hydrogen diffusion, are required for integration in the gasification plant. These membrane materials also need to be stable at temperatures above $500^{\circ} \mathrm{C}$ and high pressures $(2-3 \mathrm{MPa})$ for several thousands of hours of operation, of low cost, easy to fabricate and require minimal energy for hydrogen transport through the membrane [7, 12].

Gray \& Tomlinson, in a report prepared for US DOE in 2002, examining current and advanced technologies to produce hydrogen from coal, concluded that hydrogen can be produced from coal with current gasification technology at $\sim 64 \%$ efficiency (HHV) for production cost in the range US\$6.2-6.6/GJ. With $\mathrm{CO}_{2}$ sequestration, the cost would be US $\$ 7.8 / \mathrm{GJ}$ at $\sim 59 \%$ efficiency. By using advanced gasification technology and membrane separation, there is a potential to increase the efficiency to $\sim 75 \%$ and reduce production costs to US $\$ 5.6 / G J$. For comparison, the cost of $\mathrm{H}_{2}$ production with steam reforming of natural gas (NG) was indicated at $\sim$ US $\$ 4.55 / G J$ for a NG price of US\$2.85/GJ [13]. However, the authors stated that, to verify these claims, further research and development and performance demonstration would be required. 
Several different types of membrane technologies for integration in the gasification plant are under development and include:

- Micro and nano-porous ceramic or glass / ceramic materials: $\mathrm{H}_{2}$ is separated from other gases by molecular sieving if the pore size of the membrane material is such that smaller $\mathrm{H}_{2}$ molecules (diameter $=2.83 \AA$ ) can move freely through the pores while large molecules of other gases are restricted $[6,8]$.

- Metal membranes: Both crystalline (including nano-crystalline) and amorphous metals or alloys are under development globally to meet the requirement of integration into coal gasification plant. The mechanism for hydrogen transport through the membrane material involves hydrogen adsorption \& dissociation at the inlet surface, dissolution into the metal, diffusion in the bulk and re-association at the outlet surface. In general, crystalline metals are stable in the typical operating temperature regime of $350-500^{\circ} \mathrm{C}$ for separation of hydrogen from coal gasification products, whereas, amorphous metals may undergo transformation to a crystalline phase with time and increasing operating temperature. Degradation of most metal membranes is often observed in the presence of impurities in feed gases. Several extensive review articles are available on the subject [6-11].

- Ion transport membranes: Several ceramic materials, such as doped $\mathrm{BaCeO}_{3}, \mathrm{SrCeO}_{3}$ and $\mathrm{SrZrO}_{3}, \mathrm{CaZrO}_{3}, \mathrm{BaZrO}_{3}$ exhibit reasonable proton conductivity in the 200 to $900^{\circ} \mathrm{C}$ temperature range $[11,14-16]$. These materials can be used for the separation of hydrogen from $\mathrm{CO}_{2}$. The mechanism is the surface exchange reaction at one surface of the membrane to dissociate hydrogen, its ionization to protons, migration of protons in the membrane material and their reduction to form hydrogen molecules on the other side of the membrane. The driving force for hydrogen migration is voltage or hydrogen partial pressure differential across the membrane. Most perovskite materials which are known to have reasonable proton conductivity do not possess appreciable electronic conductivity. Ideally, the membrane material must have both proton and electronic conductivity to avoid external loading of the cell otherwise the process is very energy intensive and inefficient. In order to optimise proton / electronic conductivity, these materials may be mixed with a metal or another electronic conducting ceramic to enhance electronic conduction.

So far, Pd and its alloys are most commonly used as metal membranes for hydrogen separation in commercial devices because: Pd has good capability for hydrogen dissociation and re-association reactions; $\mathrm{Pd}$ has high hydrogen diffusivity; and formation of stable metal hydrides can be avoided $[9,17]$. However, $\mathrm{Pd}$ is an expensive and strategic material and even $\mathrm{Pd}$ membranes are known to fail in use in syngas environments containing hydrocarbons, chlorine, sulphur, mercury, etc. $[9,18]$. For these reasons, new metal membrane materials would need to minimise or avoid the use of Pd. However, many membrane materials, especially crystalline alloys, do not facilitate hydrogen dissociation and association reactions thus requiring hydrogen dissociation / association layers of Pd or Pd based alloys [9].

In general, higher fluxes are achieved with thinner metal membranes, however, this often leads to reduction in mechanical strength, thermal stability and reliability. Thus, to increase device reliability and robustness, metal membranes may need to be supported on a porous metal or ceramic support structure. If the water gas shift (WGS) catalyst is incorporated in the metal membrane hydrogen separation reactor then continuous removal of hydrogen will drive the equilibrium for the shift reaction $\left(\mathrm{CO}+\mathrm{H}_{2} \mathrm{O}=\mathrm{CO}_{2}+\mathrm{H}_{2}\right)$ forward leading to higher conversion rates $[4,5,7]$. For example, the porous ceramic or metal structure can incorporate a WGS catalyst and can be combined with a thin and dense film metal membrane to perform multiple functions of providing mechanical integrity, WGS reaction and hydrogen removal (Figure 1).

However, in order to develop suitable metal or ceramic membranes, a robust and reliable membrane reactor system is required for fast screening and evaluation of materials at high temperatures and differential pressures. In this paper, a robust design of such a membrane reactor system is described and consists of a high pressure, high temperature test fixture and seals incorporating ceramic porous structures to provide support to thin metal membranes, and the test station incorporating various control, monitoring and safety equipment. Following the design and construction of the complete system, it has been 


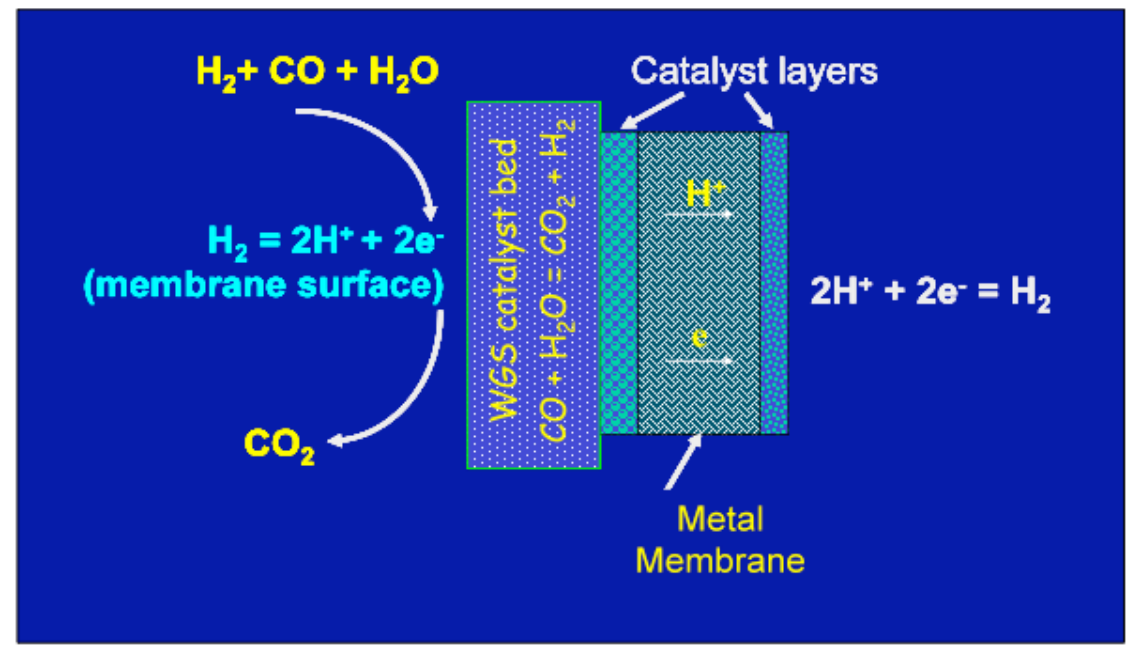

Figure 1: A schematic of the hydrogen separation membrane with Water Gas Shift (WGS) catalyst.

validated with standard $\mathrm{Pd}$ and $\mathrm{Pd} / \mathrm{Ag}$ alloy membranes as these materials are well characterised and reported in the literature for their hydrogen permeation properties.

\section{MEMBRANE REACTOR SYSTEM: DESIGN AND DESCRIPTION OF SUB-SYSTEM FEATURES}

The membrane reactor system consisted of two main parts: the high temperature and high pressure reactor with seals for fast screening / evaluation of metal and ceramic specimens and gas connections; and a test station comprising various control and monitoring equipment, gas delivery and handling, gas analysis, data logging and safety sub-systems. The overall system is described below.

\subsection{Hydrogen Permeation Membrane Reactor}

The hydrogen permeation reactor consisted of a number of components, including the test fixture which housed metal, ceramic or cermet membranes; high temperature and pressure seals; ceramic support structure; and gas delivery and exhaust connections to the test fixture.

\subsubsection{Design and Description of High Temperature, High Pressure Reactor}

A schematic of the hydrogen permeation membrane reactor is given in Figure 2. The test fixture for evaluation of test membranes is housed in a split vertical furnace and extends beyond the length of the vertical furnace case on both sides. The test fixture is located in the furnace hot zone and is comprised of the inlet and outlet chambers separated by the membrane specimen section. Both inlet and outlet chamber volumes are relatively small and the test fixture is constructed using thick metal casing and stainless steel nuts and bolts to avoid any catastrophic situation arising from specimen rupture. The removable test membrane (middle) section is sandwiched between the lower and upper chamber sections by using graphite gaskets and mechanically secured using six equispaced stainless steel nuts and bolts. The test fixture which acts as a mounting base for the membrane specimen (middle part of the membrane reactor) is a removable section. The mounting base for the specimen is a thick metal flange with a central hole exposed to the inlet chamber section of the fixture (Figure 2). On the high pressure side, the flange supports gold "O"-ring or copper gasket for the specimen sealing as described below.

Hydrogen test gas entering the inlet chamber can be pressurised by a back pressure regulator on the gas exit line to 10barG ( $G$ refers to pressure shown on the pressure gauge, $1 \mathrm{bar}=100 \mathrm{kPa}$ ). To prepare simulated gas mixtures from a range of sources, and to increase versatility of the membrane reactor, apart from the hydrogen test gas, there is also provision to supply other gases such as a premixed hydrogen / carbon dioxide gas mixture, carbon dioxide, helium or nitrogen to the inlet chamber. Alternatively hydrogen can be mixed with helium, nitrogen or carbon dioxide to generate a test gas mixture of varying composition. The outlet chamber can be provided with helium and nitrogen gases as required for either flushing the gas chamber or for diluting the permeate gas.

The main material of construction of the test fixture assembly is Inconel. Other materials used are: graphite and gold or copper gaskets for high temperature sealing, and Teflon gasket for low temperature sealing 


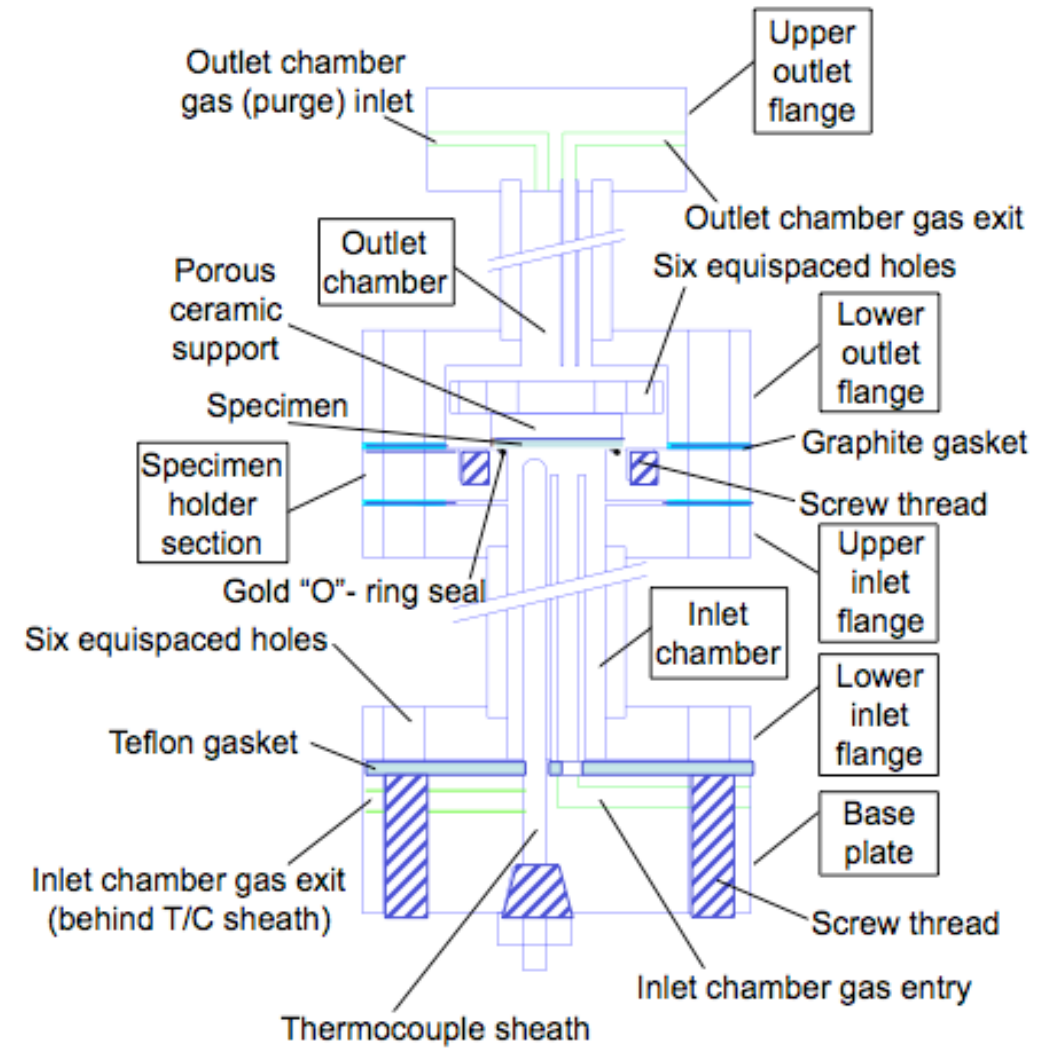

Figure 2: High temperature hydrogen permeation test fixture used in the present study.

outside the furnace; and stainless steel components required for assembly.

\subsubsection{Development and Discussion of High Temperature and High Pressure Specimen Seals}

Hydrogen separation membranes in operation experience high temperatures (up to $700^{\circ} \mathrm{C}$ ) and differential pressures (up to $30 \mathrm{bar}$ or above). Therefore, for the evaluation of metal, ceramic or cermet test membrane specimens under such conditions, special consideration had to be given to sealing materials and procedures. Gold "O"-rings (1.2mm wire cross section) seals were used for $10 \mathrm{~mm}$ to $25 \mathrm{~mm}$ diameter specimens resulting in active areas exposed to the incoming gas from 0.40 to $3.5 \mathrm{~cm}^{2}$. These seals were quite effective for metal specimens with thickness in the 20 to $500 \mu \mathrm{m}$ range. An annealed copper "washer" (22mm OD, $12.7 \mathrm{~mm}$ ID and $1.6 \mathrm{~mm}$ thick) gasket instead of the gold "O"-ring was also used and proved very effective for $200 \mu \mathrm{m}$ to $1 \mathrm{~mm}$ thick specimens. However, since the flux for hydrogen permeation decreases as the thickness of the membrane increases, for a given active area, the copper gasket was generally used for specimens with diameters larger than $14 \mathrm{~mm}$. With a $12.7 \mathrm{~mm}$ internal diameter of the copper gasket, the active area exposed to the incoming gas was $1.27 \mathrm{~cm}^{2}$. These dimensions can be altered for different size specimens. The effectiveness of both the gold "O"-ring and copper washer seals was demonstrated under the operating temperature (up to $500^{\circ} \mathrm{C}$ ) and differential pressure $(500 \mathrm{kPa})$ conditions over the period of typical testing which ranged from a few hours to a couple of days. These seals remained intact with no failure or cross leaks observed.

\subsubsection{Development and Discussion of Porous Support Structure}

Since most of the membranes for evaluation in the membrane reactor would be thin foils typically in the $20-100 \mu \mathrm{m}$ range and fragile especially in hydrogen atmosphere at high temperatures and pressures, it was considered essential to support them on a porous support which was not only stable in testing conditions, but also having the strength to tolerate high differential pressure. Moreover, the support structure had to be sufficiently porous so that it does not act as a barrier to the free flow of hydrogen. A ceramic based system based on alumina and kaolin was developed having matching Thermal Expansion Coefficient (TEC) with BCC type metals. Standard formulation and process methods for fabrication of test substrate samples have been described elsewhere in detail [19]. The sintered ceramic support structures were $27 \mathrm{~mm}$ in diameter and 

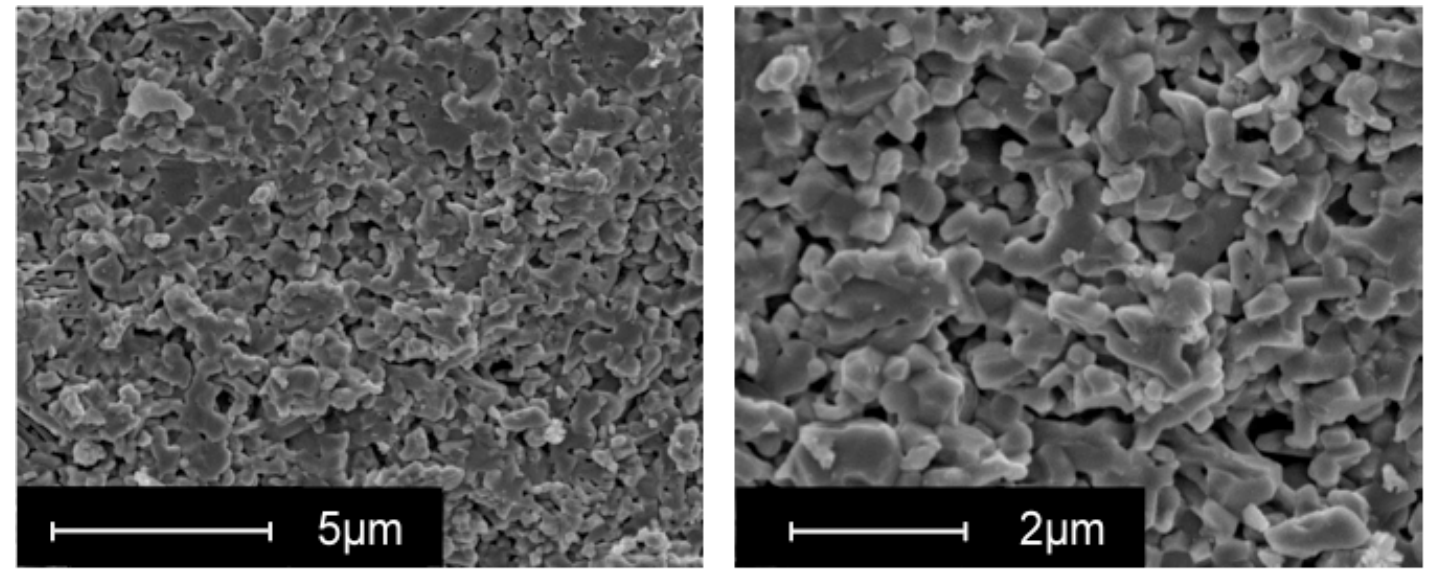

Figure 3: Scanning electron micrograph of the porous ceramic support (cross section).

2-3mm thick. Typical microstructure of the support structure is shown in Figure 3. There appears to be a fine network of open pores extending through the length of the ceramic. The support structures were tested for mechanical integrity with hydrogen as the feed gas up to a differential pressure of $500 \mathrm{kPa}$ at $500^{\circ} \mathrm{C}$ as a backing support and also at $1 \mathrm{MPa}$ differential pressure at room temperature and no damage was observed. Evaluation of the support structure for hydrogen permeation was carried out at various temperatures and differential pressures. Hydrogen flux up to $5500 \mathrm{~cm}^{3} \mathrm{~cm}^{-2} \mathrm{~min}^{-1}$ at $500^{\circ} \mathrm{C}$ and at differential pressures as low as $150 \mathrm{kPa}$ was observed as shown in Figure 4. These were considered sufficiently high flow rates not to restrict flow of hydrogen permeating through membranes to be evaluated in the membrane reactor.

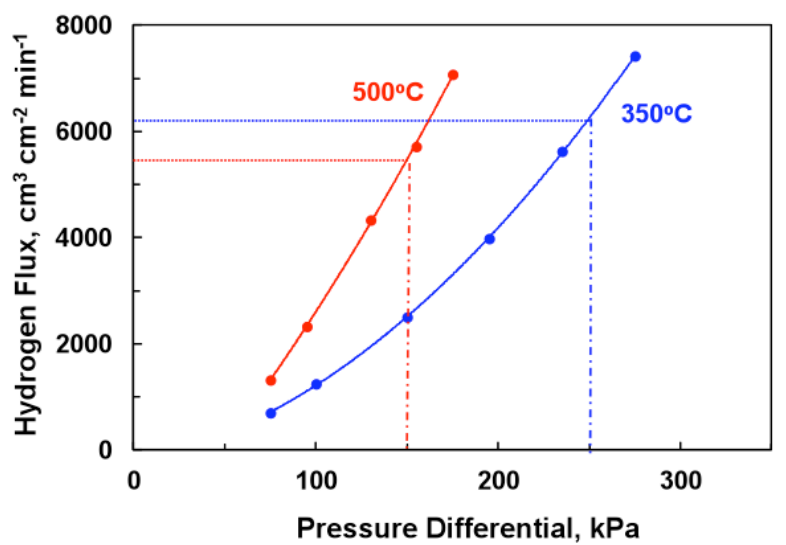

Figure 4: Hydrogen flux data as a function of temperature and partial pressure differential across the porous ceramic support structure $(100 \mathrm{kPa}=1 \mathrm{bar})$.

\subsection{Hydrogen Permeation Reactor Control Systems}

Various control and monitoring and safety subsystems have been designed, constructed and commissioned and form part of and add to the versatility of the overall test station (Figure 5) and have been discussed below. The current system has the capability to test disc specimens with an active area up to $\sim 3.5 \mathrm{~cm}^{2}$ over the temperature range of $100-800^{\circ} \mathrm{C}$ and up to $1 \mathrm{MPa}$ differential pressure across the membrane. The test station can in fact test much larger area specimens, of up to $50-100 \mathrm{~cm}^{2}$ with modification to the design of the test fixture. The test station consists of a number of sub-systems which are described in detail below.

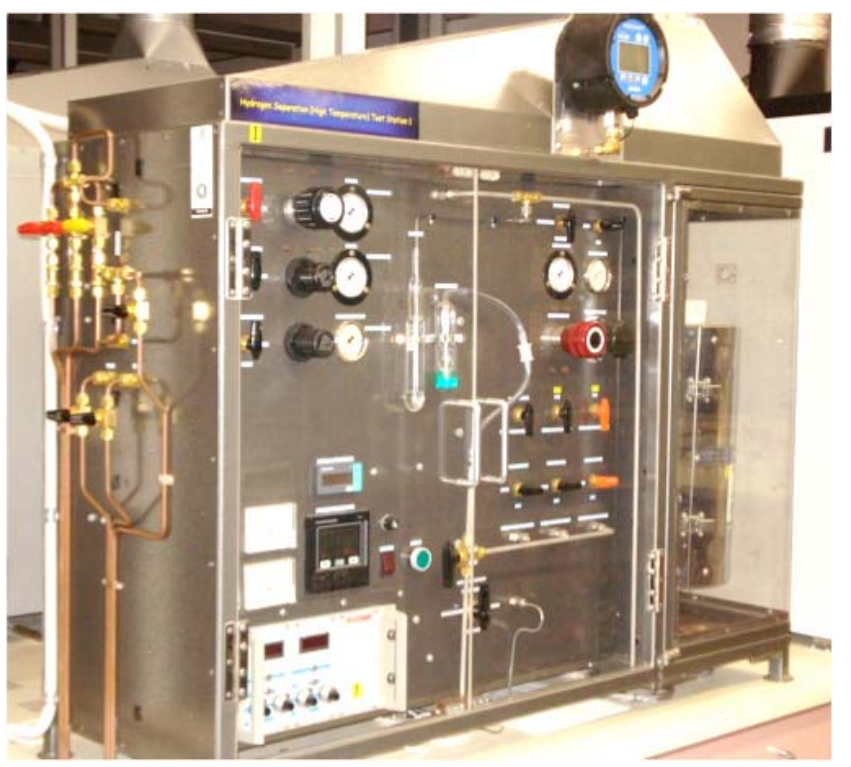

Figure 5: An image of the high temperature, high pressure, hydrogen permeation test station.

\subsubsection{Housing}

For extra safety, the station comprises of two compartments. One of the compartments is the control area and houses the furnace temperature controller, the mass flow control / read-out unit, isolation and bypass valves, gas line regulators, pressure gauges, 
pressure relief valves, back pressure regulators, sampling ports, and exit gas water-cooling jackets on both the inlet and outlet chambers of the test fixture. The second compartment houses a split vertical furnace which contains the hydrogen membrane permeation reactor described above for evaluation of test membranes.

The function of the system is to permit the evaluation / screening of various membrane materials (supported and / or unsupported) for their ability to selectively permeate hydrogen from a source gas consisting of hydrogen and other gases. The inlet chamber of the test fixture is separated from the outlet chamber by the test membrane specimen. Hydrogen gas or a mixture containing hydrogen is supplied to the test station from gas bottles or can be premixed within the test station. The hydrogen gas, or hydrogen containing gas mixture, is supplied to the inlet chamber and the flow rate of permeated hydrogen gas from the outlet chamber is monitored. The test station is connected to an exhaust duct. Hydrogen is disposed off to the atmosphere, after dilution to well below the lower explosive limit (LEL) of $4 \% \mathrm{H}_{2}$ in air, with the help of an exhaust fan with an explosion proof motor installed at the end of the duct. All exit gases are disposed off to atmosphere, via this route, from the test station.

A schematic of the flow circuit of various subsystems is given in Figure 6 . While the test station enclosure structure is located inside the laboratory, the gas sources, including the gas bottle pressure relief valves and isolation valves, solenoid valves, flashback arrestors and gas bottle non-return valves, are located outside the laboratory in a well ventilated area. The hydrogen membrane permeability reactor is shown in Figure 2 and is described in detail in Section 2.1.1. The flow circuit illustrates a number of sub-systems which are described in detail in the following sections. As shown in the circuit, before the permeate gas leaves the exit line (from the outlet chamber) to the vent, a trap was installed to stop any ambient gas diffusion coming back up the line. Other safety controls, as shown in the flow circuit, are pressure relief valves at various points in the circuit and solenoid valves which are interlocked with the vent pressure, temperature sensors in the station and $\mathrm{H}_{2} / \mathrm{CO}$ gas sensor in the laboratory. Flashback arrestors were installed at the $\mathrm{H}_{2}$ and $\mathrm{H}_{2} / \mathrm{CO}_{2}$ gas bottle sources and are shown on the schematic. A particulate filter is located on the exit side of the outlet chamber as a preventative measure to

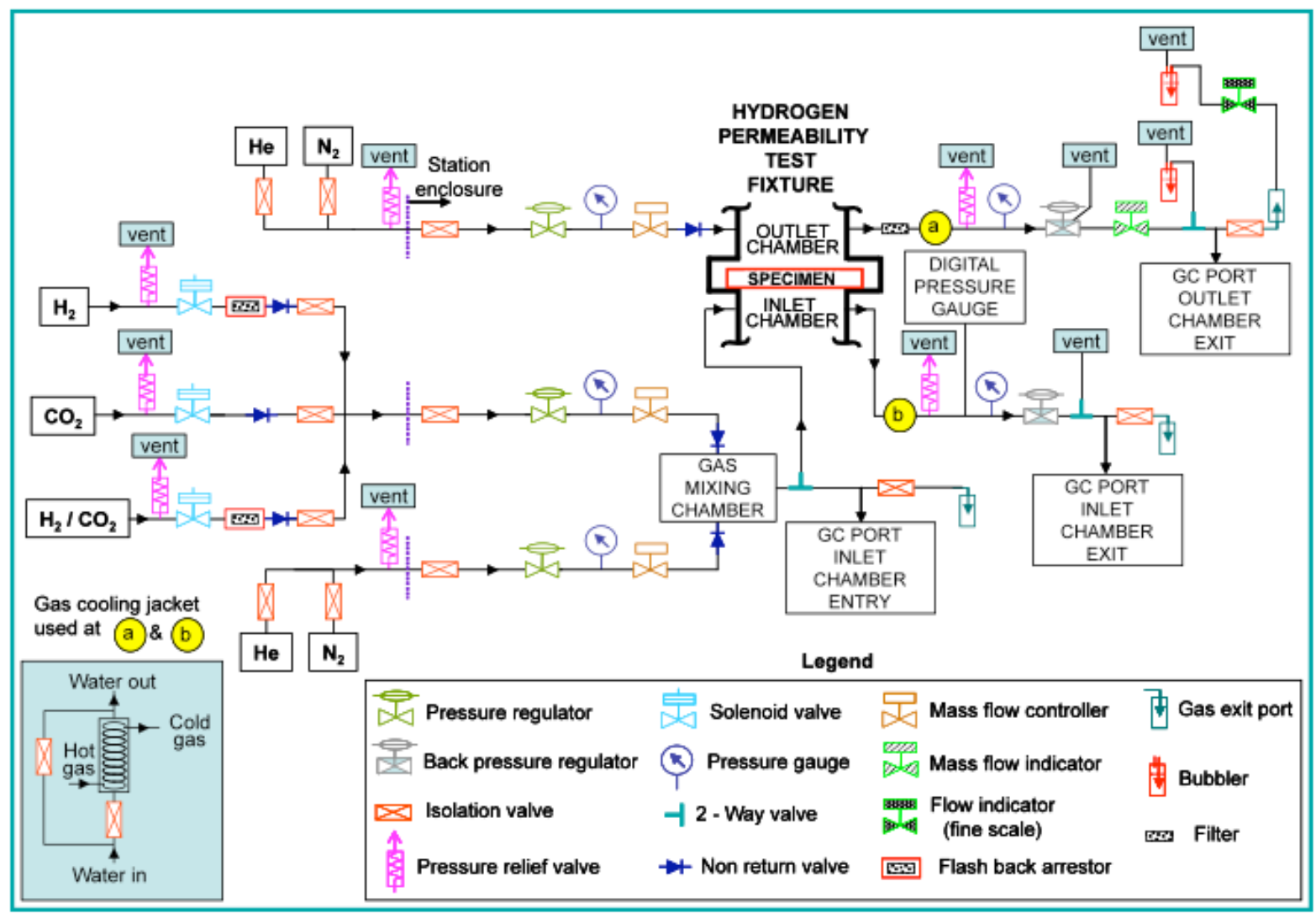

Figure 6: Flow circuit diagram of the test station as per Figure 5. 
protect the sensitive equipment downstream of the reactor in the event of a catastrophic failure occurring of either the test specimen or the porous ceramic specimen support.

\subsubsection{Gas Delivery and Mixing Sub-System}

Mass flow control / read-out unit: Three mass flow control (MFC) units were used to control the feed gas flow to the inlet and outlet chambers and one mass flow indicator (MFI) to monitor the exit gas flow from the outlet chamber. Two MFCs were used for the inlet chamber, calibrated for hydrogen (up to $5000 \mathrm{~cm}^{3} \mathrm{~min}^{-1}$ ) and nitrogen (up to $2500 \mathrm{~cm}^{3} \mathrm{~min}^{-1}$ ), and one MFC used for the outlet chamber for nitrogen as a purge / carrier gas calibrated for nitrogen (up to $2500 \mathrm{~cm}^{3} \mathrm{~min}^{-1}$ ). Furthermore, helium is also available and can pass through the nitrogen MFCs with the actual flow calculated using a conversion factor as the MFC is calibrated for nitrogen. Similarly, carbon dioxide and a premixed hydrogen / carbon dioxide mixture are also available and can pass through the hydrogen MFC for the inlet chamber. The MFI monitors the flow of the exit gas calibrated for hydrogen from the outlet chamber, which would normally be pure hydrogen, as the permeate gas resulting from the permeation of hydrogen from the dense metal membrane. A selection of additional flow (volumetric) meters are employed, on the down steam side of the above mentioned MFI, that are described in section 2.2.3. The data collected from these meters can be stored on a computer as described in section 2.2.6.

Gas mixing chamber: The test gas options available on the inlet chamber side are hydrogen, carbon dioxide, premixed hydrogen / carbon dioxide mixture, and combinations of $\mathrm{H}_{2}, \mathrm{CO}_{2}, \mathrm{H}_{2} / \mathrm{CO}_{2}, \mathrm{He}$ and $\mathrm{N}_{2}$ which can be mixed in a gas mixing chamber. The gas composition selected can be analysed prior to the entry in the inlet chamber by the gas chromatograph.

Back pressure regulators: Two back pressure regulators were located on the exit side of the chambers and are available for setting up the pressure differential across the test membrane under test, as required. Typically there was no back pressure set for the outlet chamber gas exit and the gas was simply vented to atmosphere once having passed through a bubbler acting as a trap for any back diffusion down the exit line. With the outlet chamber back pressure regulator set to zero the inlet chamber back pressure regulator could be adjusted from zero up to a maximum of $1.0 \mathrm{MPa}$.
Pressure gauges: There are a range of analogue pressure gauges which display the feed line pressures, and also the differential pressure, across the test membrane. Further to this, a digital pressure gauge is employed on the exit side of the inlet chamber for higher reading accuracy.

Non-return valves: A number of non-return valves are utilised at various locations in the circuit to avoid cross contamination of gases. This also eliminates the need for upstream flushing of the gas lines up to the location of the non-return valves.

\subsubsection{Gas Analysis and Monitoring Sub-System}

Hydrogen permeation flow rates can be measured by using a mass flow indicator calibrated for hydrogen. For finer monitoring of the exit or permeate gas, from the exit chamber, two types of flow meter have been employed. Either an Alltech Digital Flow Check (gas type selectable channels) which can measure mass flow (independent of temperature and pressure) in the range 0.1 to $500 \mathrm{~cm}^{3} \mathrm{~min}^{-1}$ for hydrogen, nitrogen, and helium, and from 0.1 to $300 \mathrm{~cm}^{3} \mathrm{~min}^{-1}$ for carbon dioxide, or a Bios Defender 510 ( $\mathrm{L}$ model with $5-500$ $\mathrm{cm}^{3} \mathrm{~min}^{-1}$ range or $\mathrm{M}$ model $50-5000 \mathrm{~cm}^{3} \mathrm{~min}^{-1}$ range) which is a volumetric meter independent of gas type. Also a Bios Definer $220 \mathrm{~L}$ model $\left(5-500 \mathrm{~cm}^{3} \mathrm{~min}^{-1}\right)$ that is similar to the Defender $510 \mathrm{~L}$ model, with the additional features of being able to measure ambient temperature and ambient pressure, can also be employed as required.

The gas analysis sub-system consisted of a gas chromatograph (Perkin Elmer ARNEL Clarus 500) which enables the analysis of the gas stream before entering the inlet chamber, upon exit of the inlet chamber, and also the permeate gas from the outlet chamber from points shown in Figure 6 . If the permeate gas flow from the exit chamber is very low, the station has the capability of including a pre-metered carrier gas (i.e. either nitrogen or helium) to increase the flow of gas to the gas chromatograph. As a precaution, on the exit side on each of the chambers, a gas watercooling jacket is employed as a safeguard prior to the gas entering the gas chromatograph as the exit gas would have been heated to a high temperature whilst in the test fixture. The gas chromatograph is provided with GC software, named Total Chrom (TC), used to control the Perkin Elmer ARNEL Clarus 500 GC. Visual analysis of the test gas is produced as a chromatogram. A method in the TC software has been calibrated for the gases to be analysed (hydrogen, 
carbon dioxide, nitrogen, carbon monoxide, methane and ethane). Using a sequence, the test is run for a 10 minute duration. The resulting data is stored on a computer disc and can be viewed at any time using the reprocessing feature of the software. A number of runs of the test gas coming from the test fixture / station (GC port inlet chamber entry, GC port inlet chamber exit or GC port outlet chamber exit points), as shown in Figure 6 , are run through the GC a number of times in order to flush the lines and achieve a reproducible analysed gas composition.

\subsubsection{Furnace, Temperature Control and Monitoring}

A vertical resistance wire wound furnace with an internal diameter of $80 \mathrm{~mm}$ was used to house the membrane reactor. The furnace itself is capable of heating the specimens to $1100^{\circ} \mathrm{C}$. However, due to restrictions from materials of construction for the test fixture and gas seal for the test fixture, an upper limit for the safe operating temperature of $800^{\circ} \mathrm{C}$ was adopted. The station houses a furnace temperature controller which displays both the furnace set temperature and the actual temperature and a specimen temperature indicator that monitors the operating temperature of the specimen membrane under test.

\subsubsection{Safety Monitoring and Control Sub-System}

The safety system has been designed with multiple levels of redundancy to safeguard against injury to the operator and damage to the equipment in the event of failure of one or more sub-systems.

\section{Gases:}

- Ventilation: The fresh air is supplied to the laboratory at flow rates ranging between 800 and 900 litres/sec. In the event of any gas leakage in the laboratory, calculations based on laboratory volume, fresh air flow into the laboratory and volume of gas in the cylinder, indicate that concentration of $\mathrm{CO}$ or hydrogen will stay well below the safe limits.

- Vent pressure sensors: There is a vent pressure sensor installed in the exhaust duct of the test station. The sensor is interlocked with the solenoid valves on the hydrogen, carbon dioxide and premixed hydrogen / carbon dioxide mixture supply lines from each of the gas bottles. In the event the exhaust fan is not running, or the exhaust suction is not sufficient, the gas supply to the test station would be turned off, and would not be available until the fault has been rectified and the safety system is reset manually.

- $\quad \mathrm{H}_{2} / \mathrm{CO}$ sensor monitoring and alarm system: A hydrogen / $\mathrm{CO}$ sensor is installed in the laboratory, near the test station, and regularly calibrated every six months by an external company. This is interlocked with the solenoid valves on the hydrogen, carbon dioxide and premixed hydrogen / carbon dioxide mixture supply lines from each of the gas bottles. A display unit outside the laboratory displays hydrogen / CO concentration all the times. The system is set in such a way that a warning light inside the laboratory is actuated at hydrogen or CO levels exceeding 40ppm in the laboratory. No other action is taken at this stage. Once the hydrogen or $\mathrm{CO}$ level exceeds 70ppm in the laboratory, an audible / visual siren located outside the laboratory is actuated and the hydrogen supply, carbon dioxide and premixed hydrogen / carbon dioxide mixture to the laboratory is turned off automatically. Hydrogen or the other gases would not be available to the laboratory until the alarm condition gas level is below 70ppm and the safety system is reset manually by an operator.

Temperature: The test station also has a temperature sensor, located in the station cabinet, interlocked with the solenoid valves on the hydrogen, carbon dioxide and premixed hydrogen / carbon dioxide mixture supply lines. In the event of temperature in the cabinet rising above the preset value, that is typically $50^{\circ} \mathrm{C}$, the gas supply to the test station would be turned off and would not be available until the temperature drops below the set value and the safety system is reset manually.

Pressure: Following safety measures have been implemented for a safe operation of the test station:

Only copper or S.S. tubing have been used for plumbing.

Pressure relief valves are installed on both sides of the membrane (inlet and outlet chambers).

A strict safe operating procedure (SOP) is followed and pressure leak testing of the plumbing and the assembled membrane cell was carried out during commissioning of the station. 
Fault indicators and reset switches: Apart from the warning lights and alarm-siren, in case of a hydrogen leakage in the laboratory above pre-set values, a safety check box for the test station has been installed. The panel on this box indicates specific potential faults (power fault, ventilation fault, temperature fault or hydrogen / CO sensor fault). Once any of the above faults occur, hydrogen, carbon dioxide and premixed hydrogen / carbon dioxide mixture are not available to the test station (or to the laboratory in the case of the gas sensor detecting gas leak) unless all safety conditions are satisfied and the reset button on the safety check box panel is manually reset.

Emergency shutdown switches: There is an emergency shutdown switch on the safety check panel and, in the event of an emergency, the operator can press this switch to stop the supply of hydrogen, carbon dioxide or premixed hydrogen / carbon dioxide to the test station.

\subsubsection{Data Acquisition}

Data logging facilities have been set-up for collecting and storing essential data during the operation of the hydrogen permeation test station. The Bios series of flow meters (using Bios Optimizer Collect Light software) are interfaced with a computer which can graphically display parameters on the monitor, such as continuous (live) volumetric flow rate, ambient temperature and pressure (depending on which Bios model is being used), and store measurements which can be further analysed. Each Bios unit can also display the above indicated parameters on a screen on the unit itself. Other parameters that are recorded manually are the furnace temperature, the specimen (chamber) temperature and differential pressures across the test specimen.

\section{COMMISSIONING OF THE MEMBRANE REACTOR AND PROCEDURE FOR MEMBRANE EVALUATION}

Commissioning and HAZOP Analysis: The entire system went through a thorough hazardous operation (HAZOP) analysis where each line of the flow circuit was evaluated against its impact for high pressures, temperatures and gas flow on the safety system. The commissioning of the membrane reactor was performed by using a solid blank non-permeating Inconel disc in place of the test specimen along with the previously described gold "O"-ring as the specimen seal and graphite gaskets sealing the upper and lower chamber sections and a Teflon gasket at the base of the reactor (as described in Section 2.1.1). The pressure testing of the inlet and outlet chamber and seal integrity was checked by separately pressurising each chamber at a time at room temperature and at temperatures up to $500^{\circ} \mathrm{C}$. At all tested pressures there were no leaks detected from either chamber thus establishing the integrity of the various sealing materials and the facility to be suitable for hydrogen permeable membrane evaluation. Functioning of the individual control and monitoring systems and the safety system for various trigger points for fail-safe operation were also performed during the commissioning phase.

Ex-situ He leak tests: Assessment of membranes in the permeation test rig (see next section) could require several hours to set up, operate and dismantle, so it was seen as desirable to quickly test membrane samples for leak tightness and to detect any flaws or pinholes prior to permeation testing. For this, an ex-situ helium leak test rig was designed and built the details of which are given in reference [20]. An ANELVA HELEN Helium Leak Detector A-210M-LD, based on a mass spectrometer tuned to relative atomic mass 4 , was used for this purpose. Tests are regularly carried out on candidate membranes prior to high temperature permeation testing to check the quality of the sourced or in-house fabricated membranes.

Pressure testing: Generally, all specimens were mounted in the membrane test assembly and underwent an initial pressure leak test at room temperature. This was to ensure the integrity of the membrane, specimen seal and the various gasket seals in the membrane reactor. For this test, the inlet chamber was pressurised up to $600 \mathrm{kPa}$ and the outlet chamber up to $300 \mathrm{kPa}$, either with $\mathrm{He}$ or nitrogen as the pressure testing gas and the gas flow was monitored on the exit gas line of the outlet chamber. In most cases the process of pressure testing was repeated once the specimen had reached the initial test temperature.

Purging outlet chamber: Since the mass flow indicator used on the exit line of the outlet chamber requires purging of the gas to be registered, otherwise the observed reading would be in error, it is necessary to purge the outlet chamber with hydrogen before actual monitoring of the hydrogen permeate flow through the mass flow indicator. Alternatively, hydrogen permeating through the membrane can be used as the purge gas provided sufficient time is given for the mass flow indicator to register a stable reading. However, 
with the Bios series of flow meters, there is no need to purge the exit line of the outlet chamber as they are in fact volumetric units and are not specific for any gas type. However, a steady state reading of flow is still required for the differential pressure condition across the test specimen.

Tracer / dilution gas: In order to check the integrity of the membrane during an experiment (e.g. hydrogen permeation flow rate measurements as a function of differential pressure across the membrane at a given temperature), nitrogen or helium can be introduced as a "tracer" or "dilution" gas in the inlet chamber along with hydrogen. This would provide an indication that the specimen is intact due to the reduction in hydrogen permeate in the presence of nitrogen or helium as a consequence of the reduced hydrogen concentration on the inlet side. This supports the hypothesis that if the membrane was leaking then no decrease in the gas flow rate on the outlet (permeate) side would be observed. Furthermore, as the molecular size of helium is quite close to that of hydrogen, if an increase in flow on the exit of the outlet chamber was observed this would suggest a physical leak across the membrane. This can be further confirmed through the use of the $\mathrm{GC}$ for the gases in question.

Table 1: Hydrogen Flux Data for Pd Based Membranes

\section{VALIDATION OF THE MEMBRANE REACTOR}

Palladium (Pd) membranes are well known for their ability to allow only hydrogen to diffuse through, with extremely high selectivity, provided there are no pin holes. The driving force for hydrogen permeation through $\mathrm{Pd}$ membranes is the hydrogen concentration gradient across it. The concentration gradient and the hydrogen flux can be enhanced by supplying pressurised hydrogen on the feed side.

The membrane reactor validation work involved investigations on the permeation of hydrogen through palladium foils with different thicknesses, in the range $22-105 \mu \mathrm{m}$, and a $\mathrm{Pd} / \mathrm{Ag}(\mathrm{Pd} 77$ / Ag23) alloy foil with a thickness of $138 \mu \mathrm{m}$, supported on porous ceramic substrates at various temperatures, between 350 and $500^{\circ} \mathrm{C}$, and hydrogen gas differential pressures between 0 and $500 \mathrm{kPa}$. Industrial grade hydrogen was used as the feed gas for all work reported here.

Table 1 summarises hydrogen flux data for various $\mathrm{Pd}$ and $\mathrm{Pd} / \mathrm{Ag}$ alloy membranes investigated in this study at two temperatures and two differential pressures. The hydrogen flux increased with increasing temperature for all membranes and with decreasing thickness for Pd membranes. However, the relationship

\begin{tabular}{|c|c|c|c|}
\hline Membrane (thickness) & Temperature $\left({ }^{\circ} \mathrm{C}\right)$ & Inlet chamber pressure (kPa, gauge) & Hydrogen flux $\left(\mathrm{cm}^{3} \mathrm{~cm}^{-2} \mathrm{~min}^{-1}\right)$ \\
\hline \multirow[t]{4}{*}{$\mathrm{Pd}(21.9 \mu \mathrm{m})$} & 497 & 500 & 22.0 \\
\hline & 497 & 250 & 10.4 \\
\hline & 344 & 500 & 14.9 \\
\hline & 344 & 250 & 6.6 \\
\hline \multirow[t]{4}{*}{$\mathrm{Pd}(48.5 \mu \mathrm{m})$} & 497 & 500 & 20.0 \\
\hline & 497 & 250 & 10.1 \\
\hline & 350 & 500 & 11.0 \\
\hline & 350 & 250 & 5.1 \\
\hline \multirow[t]{4}{*}{$\mathrm{Pd}(105 \mu \mathrm{m})$} & 498 & 500 & 13.7 \\
\hline & 498 & 250 & 7.6 \\
\hline & 353 & 500 & 9.0 \\
\hline & 353 & 250 & 5.1 \\
\hline \multirow[t]{4}{*}{ Pd77/Ag23 $(138 \mu \mathrm{m})^{*}$} & 501 & 500 & 9.4 \\
\hline & 501 & 250 & 5.1 \\
\hline & 353 & 500 & 7.5 \\
\hline & 353 & 250 & 4.1 \\
\hline
\end{tabular}

*: Membrane annealed at $550^{\circ} \mathrm{C}$ in $\mathrm{Ar}$ for 3 hours (heating \& cooling rate $300^{\circ} \mathrm{C} / \mathrm{h}$ ).

Note: The inlet chamber pressure is the set pressure indicated by the gauge with no pressure set for the outlet chamber (i.e. outlet chamber gas exit is simply vented to atmosphere) 
between the hydrogen flux and the membrane thickness was not linear and, as it will be discussed later, is most likely due to varying contributions from different rate limiting processes with changing thickness. In general, the hydrogen flux values in Table 1 are in reasonably good agreement, with those reported in the literature, considering that there is a wide variation in the method of preparation of $\mathrm{Pd}$ and $\mathrm{Pd} / \mathrm{Ag}$ membranes, self-supporting or supported on a ceramic or metal substrate, heat and surface treatments, the testing conditions (temperature, differential pressures, etc.) and different reported rate limiting processes for hydrogen transport $[9,17,18,21$ 25].

In general, various process steps for hydrogen separation on metal membranes include $[9,17,26]$ :

- $\quad \mathrm{H}_{2}$ diffusion in the gas phase to reaction sites;

- Selective adsorption \& dissociation of hydrogen at the inlet surface;

- $\quad H$ dissolution into the metal;

- $\quad \mathrm{H}$ diffusion in the bulk;

- $\quad \mathrm{H}$ diffusion along and through grain boundaries;

- Hydrogen re-association;

- $\mathrm{H}_{2}$ desorption and diffusion away from the surface on the low pressure side.

Depending on the membrane material, its thickness and other operating conditions (temperature, pressure differential, feed gas composition, surface contamination, etc.), one or more steps may determine the overall permeation rate. Typically for $\mathrm{Pd}$ membranes, in pure hydrogen feed, either hydrogen adsorption \& dissociation (surface processes) or its diffusion through the bulk are rate limiting. In the present study, hydrogen diffusion through the porous ceramic support structure (mass transport) cannot be the rate limiting step as the hydrogen flux through it was orders of magnitude higher than that in $\mathrm{Pd}$ membranes (Figure 4).

In general, the performance of a hydrogen membrane material is defined by its permeability and the gas separation factor. The permeation coefficient, $Q$, is given by

$Q=J . \delta /\left(P_{\text {in }}^{n}-P_{\text {out }}{ }^{n}\right)$ where $J$ is the hydrogen flux $\left(\mathrm{cm}^{3} \mathrm{~cm}^{-2} \mathrm{~min}^{-1}\right), \delta$ is the membrane thickness $(\mathrm{cm})$ and $P_{i n}$ is the hydrogen pressure on the feed side and $P_{\text {out }}$ is pressure (bar) on the permeate side of the membrane, and $n$ is the pressure exponent. The membrane area is included in the flux. The separation factor is the ratio of hydrogen flux to that of another gas. In the case of fully dense Pd membranes the separation factor is known to be significantly high with only hydrogen transport.

If hydrogen diffusion through the membrane is the rate limiting step then hydrogen flux through a dense metal membrane is proportional to the square root of the partial pressure differential across the membrane and $n=0.5$ (i.e. Sievert's law is followed) $[9,17,21$ 25]. Where hydrogen adsorption / dissociation or association at the $\mathrm{Pd}$ membrane surface, or gaseous diffusion, are the rate limiting steps, the hydrogen flux is directly proportional to the hydrogen partial pressure differential $(n=1.0)[17,21-23]$.

Plots of hydrogen flux data versus pressure differential across Pd membranes (Figure 7) showed that Sievert's law is followed for the $105 \mu \mathrm{m} \mathrm{Pd}$ membrane indicating that hydrogen dissolution / diffusion in the membrane is the rate limiting process $[9,17,18,21-25]$. However, for thinner membranes, a significant deviation from the Sievert's law was observed and it increased as the membrane thickness decreased (Figure 7). Table 2 shows the value of pressure exponent, $n$, as per equation (1) for different $\mathrm{Pd}$ and $\mathrm{Pd} / \mathrm{Ag}$ membranes. The values of $n$ at each temperature and each respective membrane thickness are for the best fit to the experimental data following a least squares linear regression in which the $R^{2}$ value was at least $>0.999$. There was a minor fluctuation for

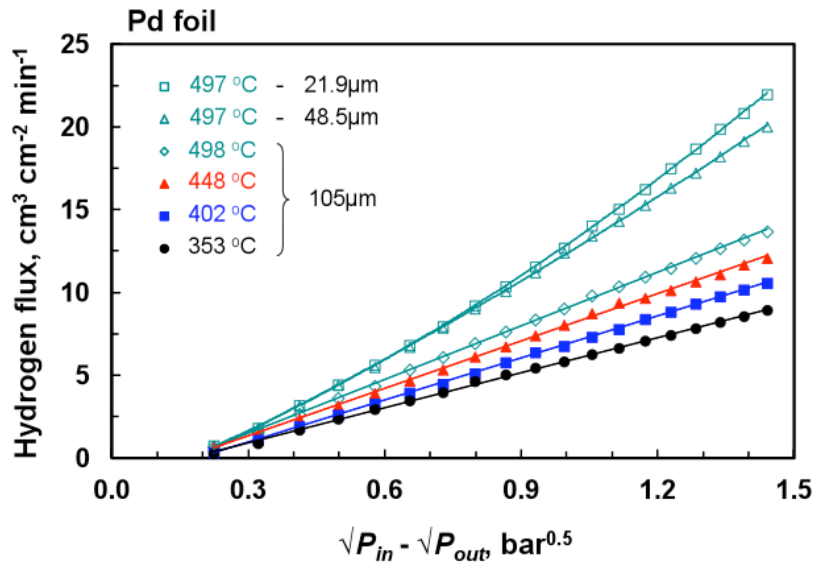

Figure 7: Hydrogen flux data for Pd membranes of different thicknesses as a function of the square root of pressure differential across the Pd membrane. 
Table 2: Pressure Exponent, $n$, as a Function of the Membrane Thickness

\begin{tabular}{|c|c|c|}
\hline Membrane (thickness) & Temperature Range $\left({ }^{\circ} \mathbf{C}\right)$ & Pressure exponent, $\boldsymbol{n}^{\star}$ in equation (1) \\
\hline \hline $\operatorname{Pd}(21.9 \mu \mathrm{m})$ & $344-497$ & $0.86 \pm 0.03$ \\
\hline $\operatorname{Pd}(48.5 \mu \mathrm{m})$ & $350-497$ & $0.67 \pm 0.07$ \\
\hline$P d(105 \mu \mathrm{m})$ & $353-498$ & $0.50 \pm 0.01$ \\
\hline$P d(103 \mu \mathrm{m})^{\star *}$ & $347-497$ & $0.57 \pm 0.01$ \\
\hline$P d 77 / A g 23^{* *}(138 \mu \mathrm{m})$ & $353-501$ & $0.60 \pm 0.04$ \\
\hline
\end{tabular}

$*: R^{2}>0.999$ for each temperature. Values given are average of four temperatures.

**: Membranes annealed at $550^{\circ} \mathrm{C}$ in Ar for 3 hours (heating \& cooling rate $300^{\circ} \mathrm{C} / \mathrm{h}$ ).

the value of pressure exponent with temperature, however, generally this variation was much lower compared with the effect of membrane thickness. Note the value of pressure exponent, $n$, for the thin $(21.9 \mu \mathrm{m})$ Pd foil membrane was slightly less than unity (i.e. $n=$ $0.86 \pm 0.03)$ and for the thicker Pd $(105 \mu \mathrm{m})$ membrane, the data were fitted to the square root pressure relationship (i.e. $n=0.50 \pm 0.01$ ). The $48.5 \mu \mathrm{m}$ thick $\mathrm{Pd}$ membrane exhibited an intermediate $n$ value of $0.67 \pm 0.07$.

Typically for thinner membranes, of the order of $10 \mu \mathrm{m}$ or less, significant deviations from Sievert's law have been reported [17, 21-25]. However, it is impossible to precisely define the membrane thickness above or below which one or the other process would be rate limiting. A number of factors such as the surface cleanliness (adsorption of other impurities and the presence of sub-surface layers), surface roughness, material purity, annealing history, and grain size and grain boundary density, can all influence the overall hydrogen permeation process $[9,17,21-25,27$ 29].

Figure 8 shows hydrogen permeation flux data, at a nominal temperature of $500^{\circ} \mathrm{C}$, as a function of pressure differential to the power $n$ relationship for $\mathrm{Pd}$ membranes of three different thicknesses. From Table $\mathbf{2}$ and Figures $\mathbf{8}$ and $\mathbf{9}$, it is obvious that for the thicker $(105 \mu \mathrm{m}) \mathrm{Pd}$ and also Pd77 / Ag23 membranes, Sievert's law is followed and hydrogen migration through the bulk contributes mainly to the rate limiting process. However, for the thinner Pd membrane $(21.9 \mu \mathrm{m})$, where the value of pressure exponent is closer to one, the prime rate limiting step appears to be associated with the hydrogen dissociation / association surface reactions. For the intermediate thickness membrane (i.e. $48.5 \mu \mathrm{m} \mathrm{Pd}$ ), the average value of $n$ is 0.67 which suggests that both surface and bulk processes are contributing to the overall rate of hydrogen transport.

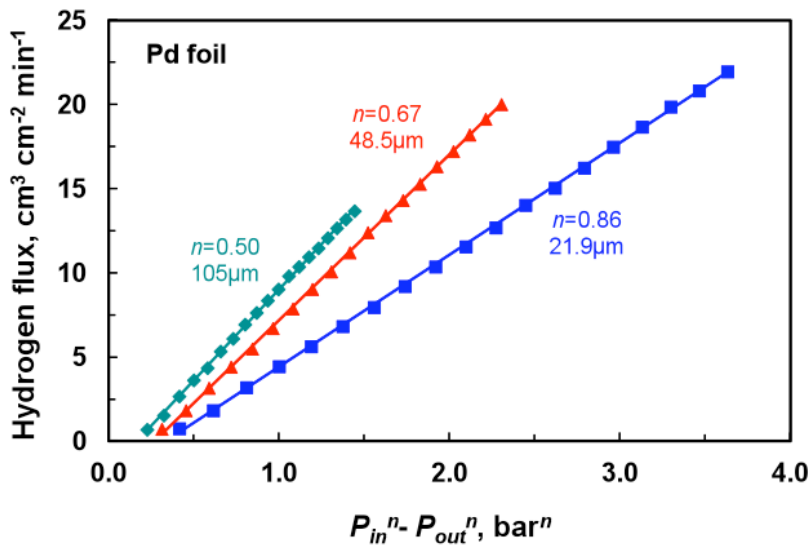

Figure 8: Hydrogen flux data at the nominal temperature of $500^{\circ} \mathrm{C}$ as a function of pressure differential for $\mathrm{Pd}$ membrane of 3 different thicknesses where the value of the pressure exponent, $n$, represents the best fit to the experimental data.

Figure 9 compares hydrogen flux data, as a function of pressure differential, for thicker $\mathrm{Pd}$ foils, before $(105 \mu \mathrm{m})$ and after $(103 \mu \mathrm{m})$, annealing at $550^{\circ} \mathrm{C}$ for $4 \mathrm{~h}$, in an argon atmosphere (heating and cooling rate $\left.300^{\circ} \mathrm{C} / \mathrm{h}\right)$, with that for $\mathrm{Pd} 77 / \mathrm{Ag} 23(138 \mu \mathrm{m})$ alloy foil annealed under identical conditions. For the $\mathrm{Pd}$ foil annealing had a detrimental effect on the hydrogen permeation flux, and the value of the pressure exponent also increased to an average value of $0.60 \pm 0.04$, indicating some contamination of the $\mathrm{Pd}$ surface, for example the formation of a surface oxide layer by the residual oxygen present in Argon (10$100 \mathrm{ppm}$ ) [30]. The hydrogen permeation flux for the thick Pd77 / Ag23 membrane was similar to that of the annealed $103 \mu \mathrm{m} \mathrm{Pd}$ membrane, and the pressure exponent was $0.57 \pm 0.01$.

The activation energy values for the permeation coefficient, $Q$, ranged between 6 and $15 \mathrm{~kJ} / \mathrm{mol}$ for various $\mathrm{Pd}$ and $\mathrm{Pd} / \mathrm{Ag}$ membranes and are well within the range reported by other authors [28, 29]. In calculating these activation energy values, the small variation in the value of pressure exponent, $n$, with temperature were ignored. However, the significance of 
activation energy is less obvious when the value of the pressure exponent, $n$ is changing, either with temperature or more clearly with the membrane thickness indicating variation in the contribution of one process over the other (surface versus bulk rate limiting processes).

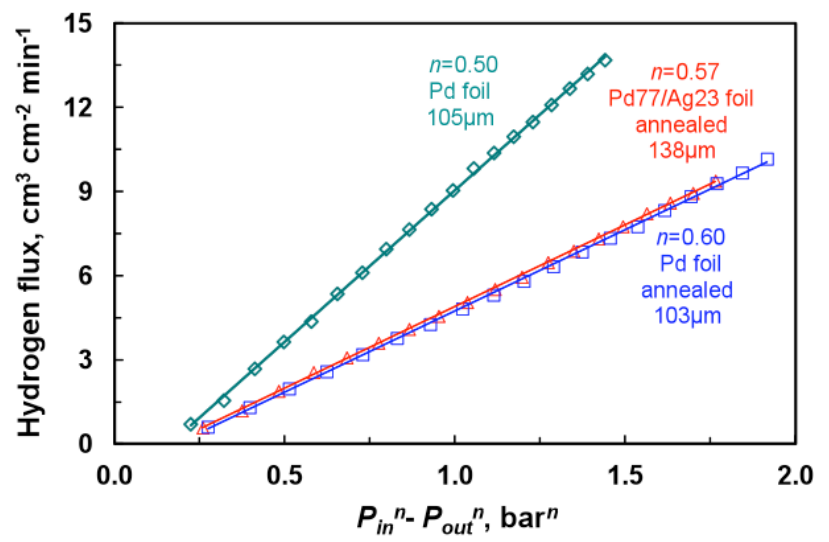

Figure 9: Comparison of hydrogen flux data at the nominal temperature of $500^{\circ} \mathrm{C}$ as a function of pressure differential for $\mathrm{Pd}(105 \mu \mathrm{m})$, and annealed $\left(550^{\circ} \mathrm{C}, 3 \mathrm{~h}\right.$ in $\left.\mathrm{Ar}\right) \mathrm{Pd}(103 \mu \mathrm{m})$ and $\mathrm{Pd} 77$ / Ag23 alloy $(138 \mu \mathrm{m})$ membranes, where the value of the pressure exponent, $n$, represents the best fit to the experimental data.

\section{CONCLUSIONS}

A versatile membrane reactor system has been described which allows fast screening and evaluation of metal and ceramic membranes for hydrogen permeation flux measurements at high temperatures to $700-800^{\circ} \mathrm{C}$ and high differential pressures across the membrane to $1 \mathrm{MPa}$. Specimens with active area in the range 0.4 to $3.5 \mathrm{~cm}^{2}$ and thicknesses from $20 \mu \mathrm{m}$ to $1 \mathrm{~mm}$ have been evaluated showing a high degree of membrane reactor flexibility. The test station, with a modified test fixture, has the capability to test specimens with an active area up to $50-100 \mathrm{~cm}^{2}$. It also has the capability to analyse entry, exit and permeate gases with a gas chromatograph and can measure flow rates for both inlet, exit and permeate gases. It has multiple levels of safety redundancy built-in. The test facility has been validated with $\mathrm{Pd}$ and $\mathrm{Pd} / \mathrm{Ag}$ alloy membranes of different thicknesses and produced hydrogen flux data comparable with those reported in the literature. Based on detailed analysis of the hydrogen flux data, the rate limiting step in the thinner $\mathrm{Pd}$ membrane was established as a surface process such as hydrogen dissociation / association, whereas for thicker membranes, the rate limiting step was determined to be hydrogen solution / diffusion process. Annealing of the membranes at $550^{\circ} \mathrm{C}$ in an $\mathrm{Ar}$ atmosphere had a detrimental effect on the hydrogen flux possibly due to surface contaminations such as the formation of a surface oxide layer.

\section{ACKNOWLEDGEMENTS}

Authors would like to thank $\mathrm{Dr}$ Sarb Giddey for assistance with the station design and HAZOP analysis and review of the manuscript, Dr Brett Sexton for making the $\mathrm{He}$ leak rate testing facility available, $\mathrm{Mr}$ Richard Donelson for assistance in the design of the permeability test fixture and He leak rate fixture and to him and Mr Bryce Wood for the supply of alumina kaolin porous ceramic substrates. The project was partially funded by the CSIRO Energy Transformed Flagship and the Centre for Low Emission Technology, Australia (c-LET).

\section{NOMENCLATURE}

$\delta \quad=$ Membrane thickness

IDGCC = Integrated drying gasification combined cycle

IGCC = Integrated gasification combined cycle

$J=$ Hydrogen flux in $\mathrm{cm}^{3} \mathrm{~cm}^{-2} \mathrm{~min}^{-1}$

$n \quad=$ Pressure exponent

$P_{\text {in }} \quad=$ Hydrogen pressure on the feed side

$P_{\text {out }}=$ Hydrogen pressure on the permeate side of the membrane

$Q \quad=$ Permeation coefficient

$\mathrm{R}^{2} \quad=$ Coefficient of determination of a linear regression

\section{REFERENCES}

[1] International Energy Outlook 2010 - U.S. Energy Information Administration. July 2010; DOE/EIA-0484. cited 2012 Nov 7: Available from: www.eia.gov/oiaf/ieo/index.html.

[2] Johnson TR. Future options for brown coal based electricity generation - the Role of IDGCC. In ANZSES Conference: Destination Renewables, Melbourne, Australia, Nov 2003. cited 2012 Nov 7: Available from: http://esvc000085.wic012u. server-web.com/melb/nov03.htm

[3] Descamps C, Bouallou C, Kanniche M. Efficiency of an Integrated Gasification Combined Cycle (IGCC) power plant including $\mathrm{CO}_{2}$ removal. Energy 2008; 33: 874-81. http://dx.doi.org/10.1016/j.energy.2007.07.013

[4] Sun Y, Hla SS, Duffy GJ, Cousins AJ, French D, Morpeth LD, et al. High temperature water-gas shift $\mathrm{Cu}$ catalysts supported on Ce-Al containing materials for the production of hydrogen using simulated coal-derived syngas., Catalysis Commun 2010; 12: 304-309.

http://dx.doi.org/10.1016/j.catcom.2010.09.025 
[5] Tang Z, Kim SJ, Reddy GK, Dong J, Smirniotis P. Modified zeolite membrane reactor for high temperature water gas shift reaction. J Membrane Sci 2010; 354: 114-22. http://dx.doi.org/10.1016/j.memsci.2010.02.057

[6] Bredesen $\mathrm{R}$, Jordal $\mathrm{K}$, Bolland $\mathrm{O}$. High-temperature membranes in power generation with $\mathrm{CO}_{2}$ capture. Chem Eng Proc 2004; 43: 1129-58.

http://dx.doi.org/10.1016/j.cep.2003.11.011

[7] Phair JW, Badwal SPS. Materials for separation membranes in hydrogen and oxygen production and future power generation. Sci Technol Adv Mater 2006; 7: 792-805. http://dx.doi.org/10.1016/j.stam.2006.11.005

[8] Lu GQ, Da Costa DJC, Duke M, Giessler S, Socolow R, Williams $\mathrm{RH}$, et al. Inorganic membranes for hydrogen production and purification: A critical review and perspective. J Colloid Interface Sci 2007; 314: 589-603. http://dx.doi.org/10.1016/j.jcis.2007.05.067

[9] Phair JW, Donelson R. Developments and design of novel (non-palladium based) metal membranes for hydrogen separation. Ind Eng Chem Res 2006; 45: 5657-74. http://dx.doi.org/10.1021/ie051333d

[10] Dolan MD, Dave NC, llyushechkin AY, Morpeth LD, McLennan KG. Composition and operation of hydrogenselective amorphous alloy membranes. J Membrane Sci 2006; 285: 30-55. http://dx.doi.org/10.1016/j.memsci.2006.09.014

[11] Phair JW, Badwal SPS. Review of proton conductors for hydrogen separation membranes. Ionics 2006; 12: 103-15. http://dx.doi.org/10.1007/s11581-006-0016-4

[12] US DOE Hydrogen from Coal Program, Research Development and Demonstration Plan for the period 2007 through 2016. September 2007. cited 2012 Nov 7: Available from: http://www.netl.doe.gov/technologies/hydrogen_clean_ fuels/refshelf/pubs/External_H ${ }_{2}$ _from_Coal_RDD_Plan_Sept ember_13.pdf

[13] Gray D, Tomlinson G. Hydrogen from coal. Mitretek Technical Paper, MTR 2002-31 (U.S. DOE NETL Contract No.: DE-AM26-99FT40465), July 2002.

[14] Kreuer KD. Proton conducting oxides. Annual Rev Mater Res 2003; 33: 333-59.

http://dx.doi.org/10.1146/annurev.matsci.33.022802.091825

[15] Reijers R, Haije W. Literature review on high temperature proton conducting materials: Electrolyte for fuel cell or mixed conducting membrane for $\mathrm{H}_{2}$ separation. ECN-E--08-091, Netherland, December 2008.

[16] Li K. Ceramic membranes for separation and reaction. John Wiley \& Sons, Ltd: England 2007. http://dx.doi.org/10.1002/9780470319475

[17] Paglieri SN, Way JD. Innovations in palladium membrane research. Sep Purif Method 2002; 31(1): 1-169. http://dx.doi.org/10.1081/SPM-120006115

[18] Bryden KJ, Ying J.Y. Nanostructured palladium-iron membranes for hydrogen separation and membrane hydrogenation reactions. J Membrane Sci 2002; 203 (1-2): 29-42.

http://dx.doi.org/10.1016/S0376-7388(01)00736-0

[19] Donelson R, Paul G, Ciacchi FT, Badwal SPS. Gas permeation characteristics of partially sintered mixtures of $\alpha$ alumina and kaolin. CSIRO Report no.: EP-29-05-12-44, May 2012.

[20] Badwal SPS, Ciacchi FT, Donelson R, Sexton B, Giddey S, Gibson $\mathrm{M}$, et al, Metal membrane hydrogen separation project progress report: CMIT (C)-2006-286, July 2006 , CSIRO Manufacturing \& Infrastructure Technology, Australia.

[21] Foletto EL, Wirbitzki Da Silveira JV, Jahn SL. Preparation of palladium-silver alloy membranes for hydrogen permeation. Latin Am Appl Res 2008; 38: 79-84.

[22] Li X, Liu TM, Huang D, Fan YG, Xu NP. Preparation and characterization of ultrathin palladium membranes. Ind Eng Chem Res 2009; 48: 2061-65. http://dx.doi.org/10.1021/ie8004644

[23] Uemiya S, Matsuda T, Kikuchi E. Hydrogen permeable palladium-silver alloy membrane supported on porous ceramics. J Membrane Sci 1991; 56: 315-25. http://dx.doi.org/10.1016/S0376-7388(00)83041-0

[24] Kikuchi E. Palladium / ceramic membranes for selective hydrogen permeation and their application to membrane reactor. Catalysis Today 1995; 25: 333-37. http://dx.doi.org/10.1016/0920-5861(95)00085-T

[25] Su C, Jin T, Kuraoka K. Thin palladium film supported on $\mathrm{SiO}_{2}$-modified porous stainless steel for a High-HydrogenFlux Membrane. Ind Eng Chem Res 2005; 44: 3053-58. http://dx.doi.org/10.1021/ie049349b

[26] Ward TL, Dao T. Model of hydrogen permeation behaviour in palladium membranes. J Membrane Sci 1999; 153: 211-31. http://dx.doi.org/10.1016/S0376-7388(98)00256-7

[27] Goto S, Assabumrungrat S, Tagawa T, Praserthdam P. Dependence of hydrogen pressure on the permeation rate through composite palladium membranes. J Chem Eng Japan 2000; 33: 330-33.

\section{http://dx.doi.org/10.1252/jcej.33.330}

[28] Huang TC, Wei MC, Chen HI. Permeation of hydrogen through palladium/alumina composite membranes. Separat Sci Technol 2001; 36(2): 199-22. http://dx.doi.org/10.1081/SS-100001075

[29] Collins JP, Way JD. Preparation and characterization of a composite palladium-ceramic membrane. Ind Eng Chem Res 1993; 32(12): 3006-13. http://dx.doi.org/10.1021/ie00024a008

[30] de Bruin HJ, Badwal SPS, Free energy of formation of PdO by impedance dispersion analysis. J Solid State Chem 1980; 34(2): 133-35.

http://dx.doi.org/10.1016/0022-4596(80)90215-7

(c) 2013 Badwal and Ciacchi; Licensee Lifescience Global.

This is an open access article licensed under the terms of the Creative Commons Attribution Non-Commercial License (http://creativecommons.org/licenses/by-nc/3.0/) which permits unrestricted, non-commercial use, distribution and reproduction in any medium, provided the work is properly cited. 